\title{
Imaging Cold-Activated Brown Adipose Tissue Using Dynamic T2*-Weighted Magnetic Resonance Imaging and 2-Deoxy-2-[18F]fluoro-D-glucose Positron Emission Tomography
}

Citation for published version (APA):

van Rooijen, B. D., van der Lans, A. A., Brans, B., Wildberger, J. E., Mottaghy, F. M., Schrauwen, P., Backes, W. H., \& van Marken Lichtenbelt, W. D. (2013). Imaging Cold-Activated Brown Adipose Tissue Using Dynamic T2*-Weighted Magnetic Resonance Imaging and 2-Deoxy-2-[ ${ }^{\circ}$ F]fluoro-D-glucose Positron Emission Tomography. Investigative Radiology, 48(10), 708-714.

https://doi.org/10.1097/RLI.0b013e31829363b8

Document status and date:

Published: 01/10/2013

DOI:

10.1097/RLI.0b013e31829363b8

Document Version:

Publisher's PDF, also known as Version of record

Document license:

Taverne

Please check the document version of this publication:

- A submitted manuscript is the version of the article upon submission and before peer-review. There can be important differences between the submitted version and the official published version of record. People interested in the research are advised to contact the author for the final version of the publication, or visit the DOI to the publisher's website.

- The final author version and the galley proof are versions of the publication after peer review.

- The final published version features the final layout of the paper including the volume, issue and page numbers.

Link to publication

\footnotetext{
General rights rights.

- You may freely distribute the URL identifying the publication in the public portal. please follow below link for the End User Agreement:

www.umlib.nl/taverne-license

Take down policy

If you believe that this document breaches copyright please contact us at:

repository@maastrichtuniversity.nl

providing details and we will investigate your claim.
}

Copyright and moral rights for the publications made accessible in the public portal are retained by the authors and/or other copyright owners and it is a condition of accessing publications that users recognise and abide by the legal requirements associated with these

- Users may download and print one copy of any publication from the public portal for the purpose of private study or research.

- You may not further distribute the material or use it for any profit-making activity or commercial gain

If the publication is distributed under the terms of Article 25fa of the Dutch Copyright Act, indicated by the "Taverne" license above,

Download date: 26 Apr. 2023 


\title{
Imaging Cold-Activated Brown Adipose Tissue Using Dynamic T2*-Weighted Magnetic Resonance Imaging and 2-Deoxy-2-[ $\left.{ }^{18} \mathrm{~F}\right]$ fluoro-D-glucose Positron Emission Tomography
}

\author{
Bart D. van Rooijen, PhD, * Anouk A.J.J. van der Lans, MS, $\dagger$ Boudewijn Brans, MD, PhD, \\ Joachim E. Wildberger, MD, PhD, * Felix M. Mottaghy, MD, PhD, $\$$ Patrick Schrauwen, PhD, $\dagger$ \\ Walter H. Backes, PhD, * and Wouter D. van Marken Lichtenbelt, PhD $\dagger$
}

Objectives: The objective of this study was to explore the use of magnetic resonance imaging (MRI) to identify and quantify active brown adipose tissue (BAT) in adult humans. 2-Deoxy-2- $\left[{ }^{18} \mathrm{~F}\right]$ fluoro-D-glucose (FDG) positron emission tomography (PET) combined with computed tomography was used as a reference method to identify active BAT depots and to guide the MRI data analysis.

Materials and Methods: The ethics committee of the institute approved the protocol, and all participants provided written informed consent before participation. Both PET combined with computed tomography and MRI of BAT were performed in 11 healthy volunteers. Brown adipose tissue was activated by cooling the participants using a dedicated water-perfused suit. For the MRI examination of BAT, water-fat imaging and dynamic T2* imaging were performed at an effective temporal resolution of 2 minutes per volume. Water-fat images were derived from a multiecho MRI sequence using the Dixon technique.

Results: 2-Deoxy-2-[ ${ }^{18}$ F]fluoro-D-glucose-PET identified active BAT in 8 of the 11 participants. Water-fat MRI showed that BAT depots had a fat fraction of $65.2 \%(7.0 \%)$ compared with $81.5 \%(5.4 \%)$ for the subcutaneous white adipose tissue (paired difference of $16.3 \%$ [4.9\%]; $P<0.05$ ). Dynamic T2* imaging during cold stimulation revealed signal fluctuations that were sensitive to BAT activation. The presence of these components correlated with BAT activation quantified from FDG-PET $(r=0.63 ; P<0.05)$.

Conclusions: Although FDG-PET has superior contrast for identifying active BAT, the MRI temporal resolution provides insight in activation dynamics. In addition, the flexibility of MRI allows for simultaneous mapping of tissue fat content and functional responses. The results indicate that MRI is a promising addition to PET for the identification of BAT and its activity responses to stimulation. An MRI-based methodology to quantify BAT activity is a highly desirable step in addressing the role of BAT in obesity disorders.

Key Words: brown adipose tissue, magnetic resonance imaging, positron emission tomography, thermogenesis

(Invest Radiol 2013;48: 708-714)

$\mathrm{M}$ ammals have 2 distinct types of fat tissue: white adipose tissue (WAT) and brown adipose tissue (BAT). Brown adipose tissue is strongly innervated by the sympathetic nervous system and is

Received for publication November 12, 2012; and accepted for publication, after revision, February 24, 2013.

From the *Department of Radiology, Maastricht University Medical Center, $\uparrow$ Department of Human Biology and Nutrition and Toxicology Research Institute Maastricht, Maastricht University, †Department of Nuclear Medicine, Maastricht University Medical Center, Maastricht, The Netherlands; and §Department of Nuclear Medicine, University Hospital Aachen, Aachen, Germany.

Supported partly by the Netherlands Organization for Scientific Research (TOP 91209037) to WDvML and by the European Union FP7 project DIABAT (HEALTH-F2-2011-278373).

The authors report no conflicts of interest.

Supplemental digital contents are available for this article. Direct URL citations appear in the printed text and are provided in the HTML and PDF versions of this article on the journal's Web site (www.investigativeradiology.com).

Reprints: Walter H. Backes, PhD, Department of Radiology, Maastricht University Medical Center, PO Box 5800, 6202 AZ, Maastricht, The Netherlands. E-mail: w.backes@mumc.nl.

Copyright $(C) 2013$ by Lippincott Williams \& Wilkins

ISSN: 0020-9996/13/4810-0708 much more densely vascularized than WAT. ${ }^{1}$ Brown adipose tissue is the main site for nonshivering thermogenesis (NST) in rodents. ${ }^{2,3}$ Only recently, it was shown by positron emission tomography (PET) using 2-deoxy-2- $\left[{ }^{18} \mathrm{~F}\right]$ fluoro-D-glucose (FDG) that adult humans possess functionally active BAT depots and that the presence of active BAT influences human metabolism. ${ }^{4}$ It has thus been postulated that pharmaceutical targeting of BAT is a possible strategy in the treatment of obesity.

The only noninvasive method to investigate the presence of BAT has been the use of FDG-PET combined with computed tomography (CT). Although this method offers excellent sensitivity in detecting active BAT, the use of ionizing radiation limits its application on healthy human participants in research. In addition, because FDG uptake is an irreversible process, obtaining information about the dynamics of BAT activation, such as on/off switching, is difficult. To complement these shortcomings, an additional noninvasive method is needed.

Brown adipose tissue imaging using magnetic resonance imaging (MRI) has been mainly performed on rodents. Results from both fat imaging ${ }^{5-7}$ and perfusion imaging ${ }^{8,9}$ suggest that MRI might be a valuable tool for identifying BAT depots and characterizing BAT activation. More recently, human BAT was identified using MRI in a human infant. ${ }^{10}$ The aim of this study was to investigate whether MRI can be used to characterize active BAT depots in adult humans for water-fat composition and activity response to cold conditions. On the basis of reported results, we hypothesized that, in MRI, both water-fat imaging and perfusion imaging are sensitive to the presence of active BAT. In this study, MRI was used to assess BAT fat content (as measured by a multiecho MRI acquisition ${ }^{11}$ ) and BAT activation using dynamic $\mathrm{T} 2 *$ imaging during cold exposure. In the same participants, FDG-PET/CT during cold stimulation was performed as the reference method for BAT activity.

\section{MATERIALS AND METHODS}

The ethics committee of the institute approved the protocol, and all participants provided written informed consent before participation.

\section{Study Population}

Healthy human participants with an age between 18 to 30 years and a body mass index between 18 to $30 \mathrm{~kg} / \mathrm{m}^{2}$ were eligible for the study. Exclusion criteria were known diabetes mellitus, the use of $\beta$-blockers, and contraindications to MRI or ionizing radiation. Eleven young adults ( 7 women and 4 men) participated in the study. See Table 1 for the participants' characteristics.

\section{Study Design}

All participants underwent a cooling trial experiment, a full MRI protocol, and an FDG-PET/CT. Within 5 days of the trial, MRI and, within 9 days, FDG-PET/CT were performed. For the trial experiment, MRI and PET/CT were performed after a fasting period of at least 5 hours. 
TABLE 1. Characteristics of the Study Participants

\begin{tabular}{lcc}
\hline Characteristic & Value & Range \\
\hline Men/women & $4 / 7$ & \\
Age, $\mathrm{y}$ & $23.9(2.2)$ & $21-28$ \\
Body mass, kg & $72.4(13.4)$ & $50.7-99.0$ \\
Height, $\mathrm{m}$ & $1.8(0.1)$ & $1.7-1.9$ \\
BMI, $\mathrm{kg} / \mathrm{m}^{2}$ & $22.9(3.2)$ & $18.2-27.7$ \\
Body fat, \% & $27.0(7.9)$ & $9.6-35.8$ \\
\hline
\end{tabular}

Data are reported as mean (SD).

BMI indicates body mass index.

\section{Individualized Cooling Protocol}

Cooling was performed by wrapping the participant in a waterperfused suit (Thermowrap, Universal MTRE System) connected to 2 temperature-controlled water baths (Blanketrol III, Cincinatti SubZero) comparable with the study of Ouellet et al. ${ }^{12}$

The cooling protocol was adjusted to the individual participant's response in the trial experiment. The participants were sequentially exposed to 30 minutes of thermoneutral conditions, cooling until shivering, warm conditions for 5 minutes, and mild cold conditions $\left(20.4^{\circ} \mathrm{C}\right.$ $\left[1.7^{\circ} \mathrm{C}\right]$ ) for 60 minutes. When the participant reported shivering during the mild cold condition, suit temperature was increased in steps of $1{ }^{\circ} \mathrm{C}$ until no obvious muscle cramps or shivering was reported. When the participant did not report feeling cold, suit temperature was lowered in steps of $1^{\circ} \mathrm{C}$.

The optimal water temperature for NST resulted in suit temperatures in a range of $22.4^{\circ} \mathrm{C}$ to $26.3^{\circ} \mathrm{C}\left(24.1^{\circ} \mathrm{C}\left[1.4^{\circ} \mathrm{C}\right]\right)$. This individual mild cold condition was used during the PET/CT and the dynamic $\mathrm{T} 2 *$ imaging. In few cases, the individuals reported shivering under mild cold conditions while scanning; in response, suit temperature was raised by $1^{\circ} \mathrm{C}$.

\section{2-Deoxy-2-[18F]fluoro-D-glucose-PET/CT Acquisition}

Before the PET/CT scan, the participants were kept in thermoneutral conditions for 45 minutes, followed by cooling until shivering and
5 minutes of warming. Subsequently, the participants were exposed to mild cold for 90 minutes, with injection of $74 \mathrm{MBq}$ of FDG intravenously after 30 minutes. Hereafter, the imaging started with a CT, followed by a PET scan (Gemini TF PET-CT; Philips, Best, The Netherlands). The resulting total effective radiation dose for the full examination was approximately $2.8 \mathrm{mSv}$. The PET scan covered the neck to the kidneys, requiring 6 to 7 bed positions ( 6 minutes per bed position). The CT scan was used for attenuation correction of the PET scan and localization of the FDG uptake sites. A tube voltage of $120 \mathrm{kV}, 30 \mathrm{~mA}$ s per slice, and $64 \times 0.625 \mathrm{~mm}$ of collimation was used. Both image sets were reconstructed with a slice thickness of $4 \mathrm{~mm}(130$ to 170 slices). The in-plane resolution was $4 \mathrm{~mm}$ for the PET and $1 \mathrm{~mm}$ for CT. The images were analyzed using PMOD (PMOD Technologies, Zürich, Switzerland). With this software, BAT activity was quantified by contouring the BAT areas with a set threshold. These regions of interest (ROIs) were verified by an experienced nuclear medicine physician.

\section{Magnetic Resonance Imaging Acquisition}

Magnetic resonance imaging acquisitions were conducted on a Philips Achieva 3.0T scanner (Philips, Best, The Netherlands). An 8-element neurovascular coil was used. The scans were positioned to include the supraclavicular and cervical adipose depots (14-cm field of view along the caudal-cranial axis). No respiratory compensation was used. The participants were wrapped in the water-perfused suit. All participants underwent the MRI protocol, which consisted of a $\mathrm{T} 1$ sequence, water-fat imaging, and followed by dynamic $\mathrm{T} 2 *$ imaging during which a cooling paradigm was performed. Before the cooling experiment, the participants were kept in thermoneutral conditions. The T1-weighted turbo gradient echo sequence had the following parameters: repetition time (TR), 10 milliseconds; echo time (TE), 2.3 milliseconds; flip angle (FA), 15 degrees; field of view (FOV), $246 \mathrm{~mm}$ anteriorposterior (AP), $450 \mathrm{~mm}$ right-left $(\mathrm{RL})$; matrix, $320 \times 320$; slice thickness, $7 \mathrm{~mm}$; slice gap, $1 \mathrm{~mm}$; slices, 25; and acquisition time, 1 minute.

For water-fat imaging, a triple echo (for $\mathrm{T} 2 *$ correction $^{13}$ ) gradient echo acquisition was performed. From the images containing either the sum (in-phase) or the difference (out of phase) of the water and fat signal, separated water and fat images were derived by the scanner software. ${ }^{11,14}$ The method was validated by measurements on a phantom (see Supplemental Digital Content Fig. S1, Supplemental Digital
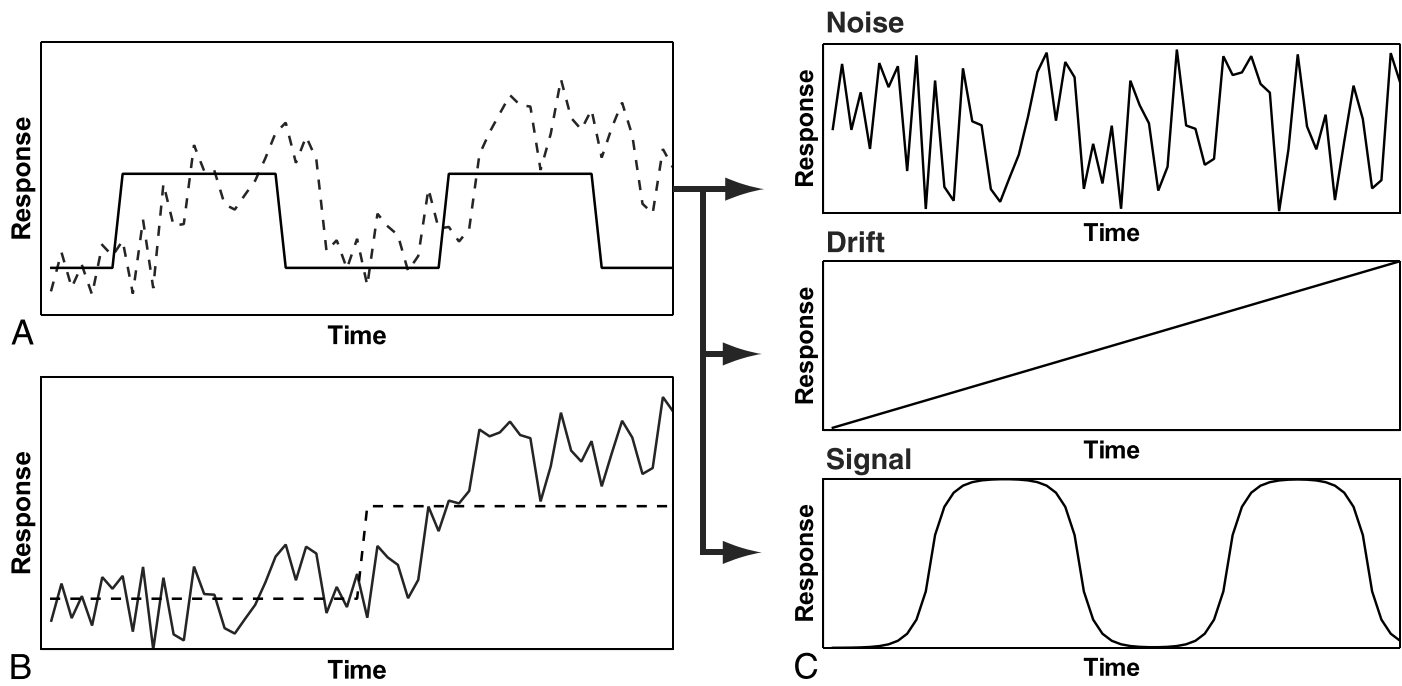

FIGURE 1. Time-series analysis. A, The repeated cooling paradigm in the dynamic T2* MRI acquisition was repeated twice (solid line) to create four transitions in signal level. In the presence of noise and signal drift (dashed line), this improves the contrast to noise of the signal recovery. B, A single repetition of the paradigm would result in a poor contrast to noise ratio possibly more confounded by signal drifts. C, The ICA analysis is able to separate different independent components from a mixed signal. 
Content 1, http://links.lww.com/RLI/A86). ${ }^{15}$ The following parameters were used: TR, 289.9 milliseconds; TE1, 2.3 milliseconds (in-phase); TE2, 3.45 milliseconds (opposed phase); TE, 34.6 milliseconds (inphase); FA, 75 degrees; FOV, $372 \times 465 \mathrm{~mm}(\mathrm{AP} \times \mathrm{RL})$; reconstruction matrix, $260 \times 231$; slice thickness, $6 \mathrm{~mm}$; slice gap, $1 \mathrm{~mm}$; slices, 20; and acquisition time, 2 minutes.

Dynamic T2*-weighted imaging was performed using gradient echo planar imaging with the following parameters: TR, 200 milliseconds; TE, 15 milliseconds; FA, 90 degrees; FOV, $204 \times 450 \mathrm{~mm}(\mathrm{AP} \times \mathrm{RL})$; reconstruction matrix, $300 \times 298$; slice thickness, $2 \mathrm{~mm}$; slice gap, $5 \mathrm{~mm}$; and 20 slices resulting in an acquisition time per single volume of 15 seconds. During the acquisition, no breath-hold, cardiac, or respiratory triggering was used. Two minutes after the start of the dynamic $\mathrm{T} 2 *$-weighted acquisition, the participants were cooled until shivering and were subsequently warmed for 5 minutes. After this, the participants were exposed to mild cold for 10 minutes, followed by 15 minutes of thermoneutral condition. The whole paradigm was subsequently repeated to modulate the response with a characteristic temporal signature, which improves possible signal detection with respect to background fluctuations (Figs. 1A, B). The duration of the protocol varied between the participants (depending on the time in which the participants reported shivering) and was in the range of 46 to 86 minutes.

\section{Time-Series Analysis}

Preprocessing of the dynamic T2*-weighted acquisition was performed in MATLAB. Image noise was reduced by averaging 8 subsequent volumes. This results in an effective temporal resolution of approximately 2 minutes per volume. Motion correction was performed by using a 2-dimensional nonrigid b-spline registration. ${ }^{16}$

Because there is limited a priori knowledge of the temporal characteristics of BAT activation, the expected tissue time response in the dynamic acquisition is not known. To identify possible responses without prior knowledge of the time signature, an independent component analysis (ICA) was performed using MELODIC. ${ }^{17-19}$ Independent component analysis is a mathematical data-driven method to decompose a signal into statistically independent temporal components (Fig. 1C). The response could, for instance, be delayed or distorted compared with the stimulus. In a direct regression with the stimulus, the contrast may then be lost. The images were masked with an ROI representing activated BAT found on PET/CT. The ROI was delineated
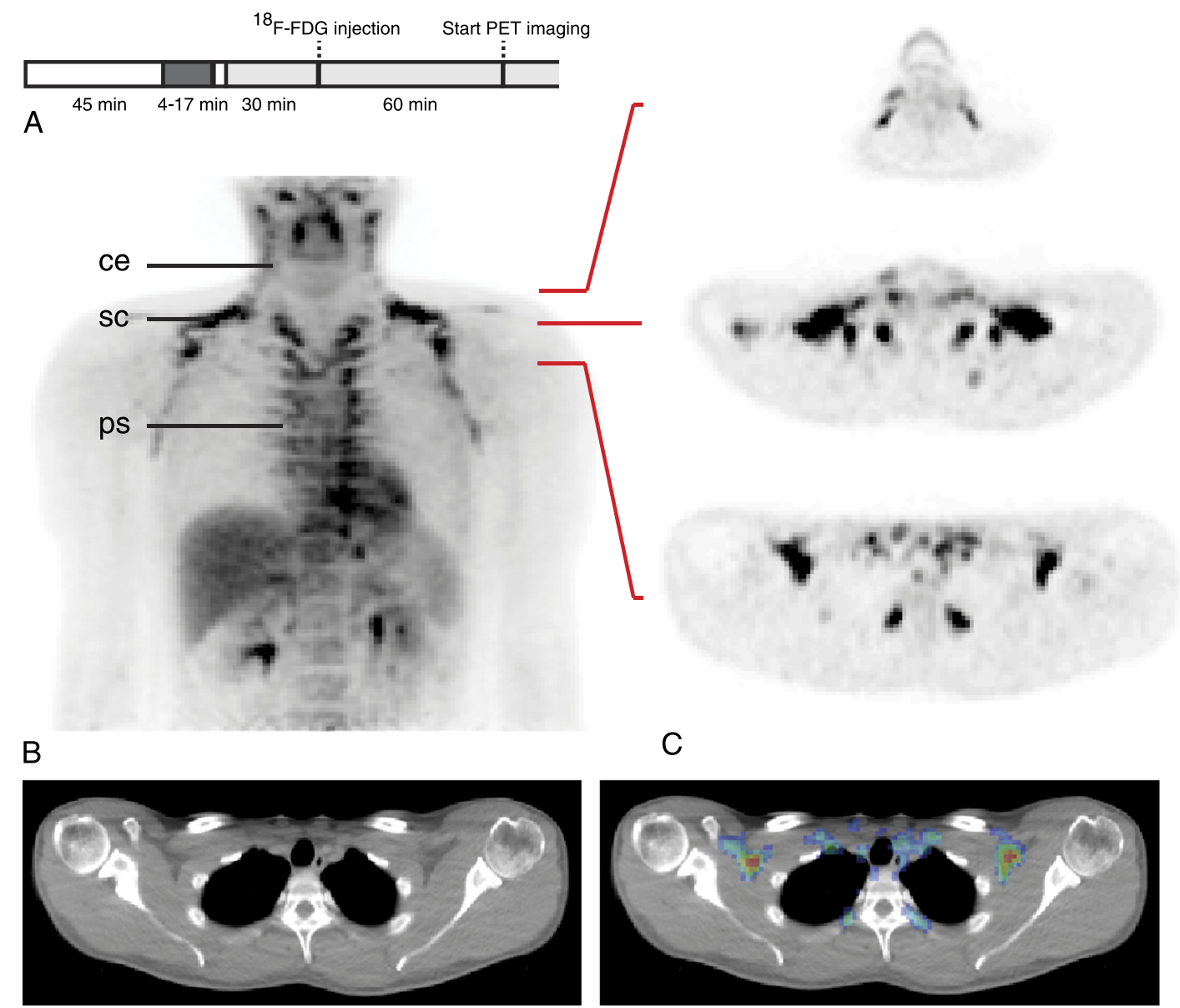

E

FIGURE 2. 2-Deoxy-2-[18F]fluoro-D-glucose-PET/CT of activated BAT. A, Cooling protocol for BAT imaging using PET. The participants were cooled (dark grey) before FDG injection and exposed to NST (light grey) conditions during the imaging. Thermoneutral conditions are depicted with a white fill. B and C, Positron emission tomography of a BAT+ participant showing a typical FDG uptake distribution. B, The supraclavicular (sc), cervical (ce), and paraspinal (ps) depots are clearly observed in the coronal projection. Note that the heart and the liver also show displayed FDG uptake. C, Corresponding axial slices at different levels marked by the red lines. D, Axial slice of the low-dose CT. E, Overlay of the corresponding PET slice on the low-dose CT. 
on the T1-weighted scan on the basis of the corresponding PET/CT slice including supraclavicular and cervical depots. The ROIs were drawn by an experienced imaging researcher and under the supervision of a physician who has specialty in nuclear medicine.

In addition, a model-based analysis was performed with the FEAT linear regression analysis tool from the FSL software package. ${ }^{18,19}$ The response was modeled as a block wave derived from the time signature of the cooling protocol and has a value of 1 during cooling and 0 during heating and thermoneutral periods. Multiple regression with this model was performed on each voxel. The regression results are represented as z-maps containing the z-score for the probability that the model is an accurate representation of the corresponding voxel time trace.

\section{Statistical Analysis}

Descriptive results are reported as mean (SD). Comparison of tissue fat content was performed using a (2-tailed) paired Student $t$ test. The threshold in the analysis of the activation maps was set at a z-score of 1.65. The MRI and PET results in the supraclavicular and cervical depots were compared by calculating the Pearson correlation coefficient between the fraction of activated voxels in dynamic $\mathrm{T} 2 *$-weighted imaging and the activity concentration measured by PET/CT. Correlations coefficients were tested for significance $(P<0.05)$ against the null hypothesis.

\section{RESULTS}

\section{Positron Emission Tomography/Computed Tomography}

On the PET images, 8 of the 11 participants showed a pronounced FDG uptake in BAT. For 3 participants, the FDG uptake was negligible, and these participants did not have common characteristics. A typical distribution of FDG uptake is shown in Figures $2 \mathrm{~B}$ and C. Uptake in the supraclavicular, cervical, and paraspinal depots was observed. These depots can be identified as adipose tissue on the fused PET/CT image because adipose tissue has Hounsfield units in the range of -150 to -50 (Fig. 2D).

\section{Water-Fat MRI}

The fat depots identified on T1-weighted magnetic resonance images corresponded visually with the regions identified on the CT scan (Figs. 3A, B). On water-fat MRI (Fig. 3C), the adipose tissue could clearly be observed as regions with a high pixel intensity. Figure $3 \mathrm{E}$ shows the distribution of the voxel fat content of the subcutaneous WAT compared with that of the internal fat depots in the supraclavicular and cervical regions. The supraclavicular/cervical fat depots containing BAT showed a lower fat content compared with that of the subcutaneous WAT. The mean (SD) fat content in all participants was $65.2 \%(7.0 \%)$ for the supraclavicular/cervical fat depots compared
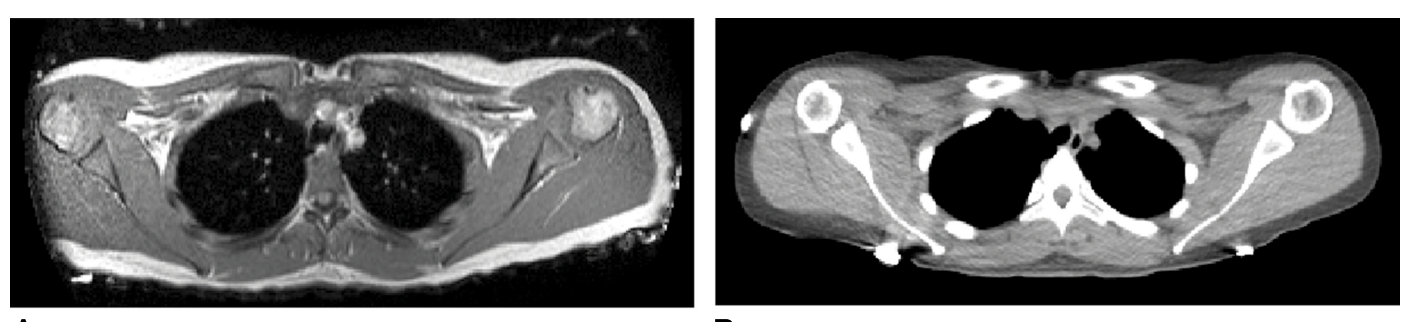

A

B
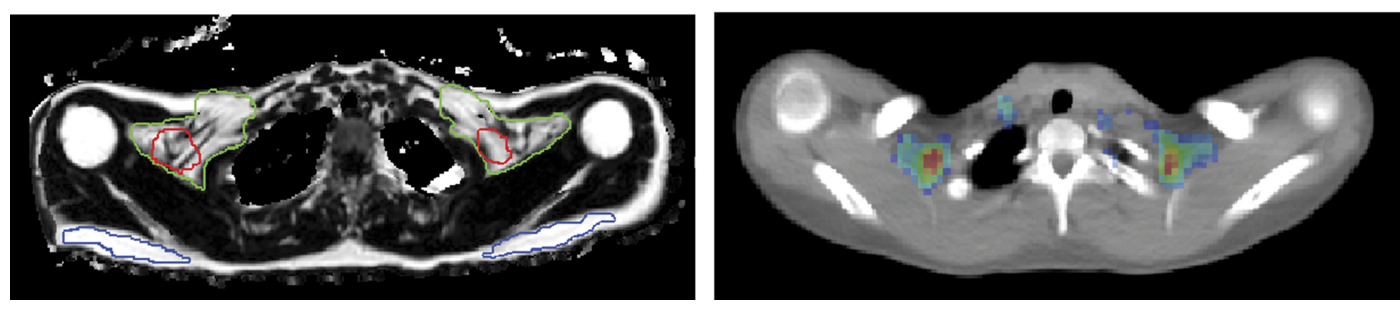

C

D

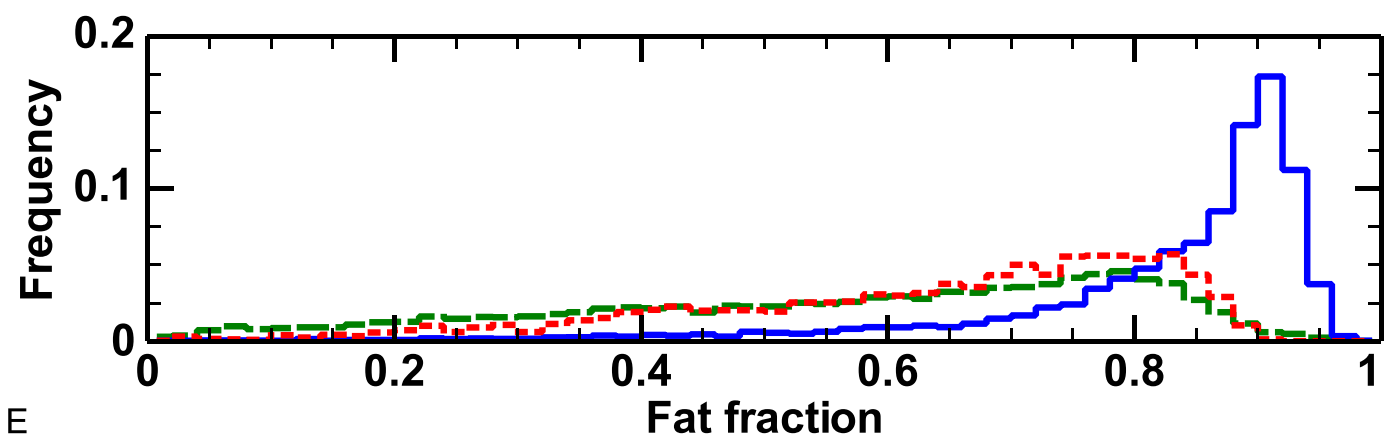

FIGURE 3. Water-fat MRI of BAT. A, Axial slice of a T1-weighted MRI scan. B, Corresponding axial slice of the low-dose CT scan. $C$, Axial slice of the fat content image of a BAT+ participant. The green contour denotes the complete supraclavicular fat depot, the red contour indicates the region showing FDG uptake on the PET, and the blue contour is the ROI used as the subcutaneous WAT. D, Axial PET/CT slice corresponding to the fat content image in (C). The FDG uptake is not homogeneous throughout the adipose depot. $\mathrm{E}$, Normalized histogram of the fat content of voxels in the different ROls described in (C), representing the subcutaneous WAT (blue line), the supraclavicular/cervical fat depot (green dashed line), and the region showing the FDG uptake (red dotted line). 
with $81.5 \%$ (5.4\%) for WAT with a paired difference of $16.3 \%(4.9 \%$; $P<0.05)$. The supraclavicular/cervical fat depots are morphologically different from the subcutaneous WAT. The subcutaneous WAT appeared homogeneous, whereas the supraclavicular/cervical depots were much more heterogeneous (Fig. 3C). This is also reflected in the width of their respective fat content distributions (Fig. 3E). The PET/ CT images (Fig. 3D) showed that the active BAT is only present in parts of the supraclavicular/cervical fat depots. Therefore, the fat distribution analysis was also performed including only regions that showed FDG uptake on the PET/CT images. The resulting fat content for BAT was $66.0 \%(9.3 \%)$, which was similar to the complete supraclavicular/cervical depot. The mean (or median) of the fat distribution of the supraclavicular/cervical fat compartments did not correlate with the FDG uptake.

\section{Brown Adipose Tissue Activation by Dynamic T2*-Weighted Imaging}

Dynamic $\mathrm{T} 2 *$-weighted imaging was used to measure physiological changes in BAT during cold exposure (Figs. 4A-C). The MRI time signal showed large fluctuations within the supraclavicular/ cervical depot (Fig. 4D). The signal responses had a large heterogeneity in time signature (Fig. 4E). In most participants, several voxel clusters could be found, in which fluctuations correlated with the cooling protocol. To independently validate the presence of such a component, the ICA was performed. The ICA identified a component with similar temporal characteristics (Fig. 5A). No other consistent components could be identified. Subsequently, regression with a modeled response of this component was performed (Fig. 5B). Some activating voxels were also found outside the ROI because the activation maps had a noisy appearance. Figure $5 \mathrm{C}$ shows that the fraction of activating voxels in the fat depot correlated with the activity concentration of FDG uptake of BAT in the PET image. This correlation existed both for voxels that showed an activation pattern similar to the model and for voxels that showed an activation pattern with the opposite sign. T2*-weighted contrast thus seems to be sensitive to local tissue reactions that correlate with BAT activation and deactivation. As a control, the activation in muscle and WAT was also assessed. The fraction of activating voxels in these tissues did not significantly correlate significantly with the FDG activity concentration in the participants (Fig. 5C).

\section{DISCUSSION}

Recent work has shown that water-fat imaging is useful to identify BAT in animal models $\mathrm{s}^{5,6,8,9}$ and in human newborn. ${ }^{10}$ The

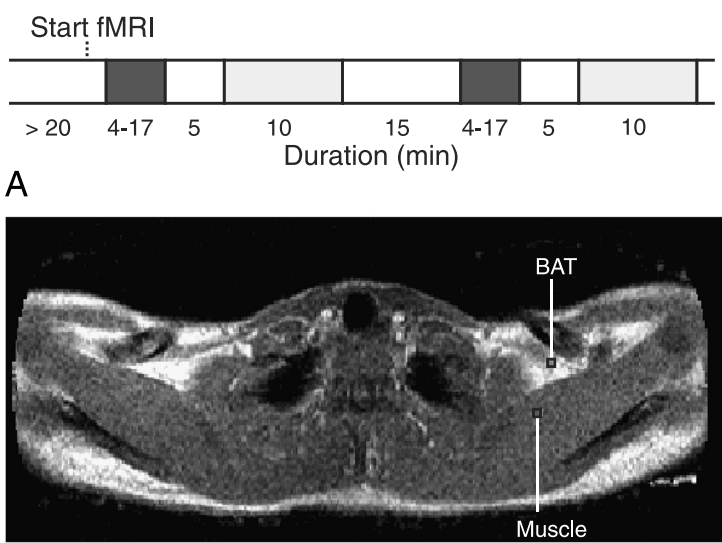

B

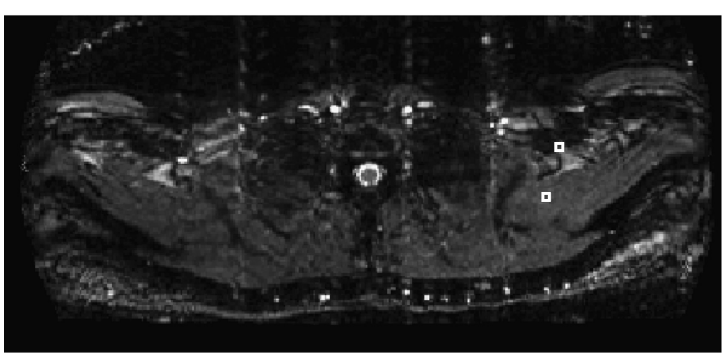

C
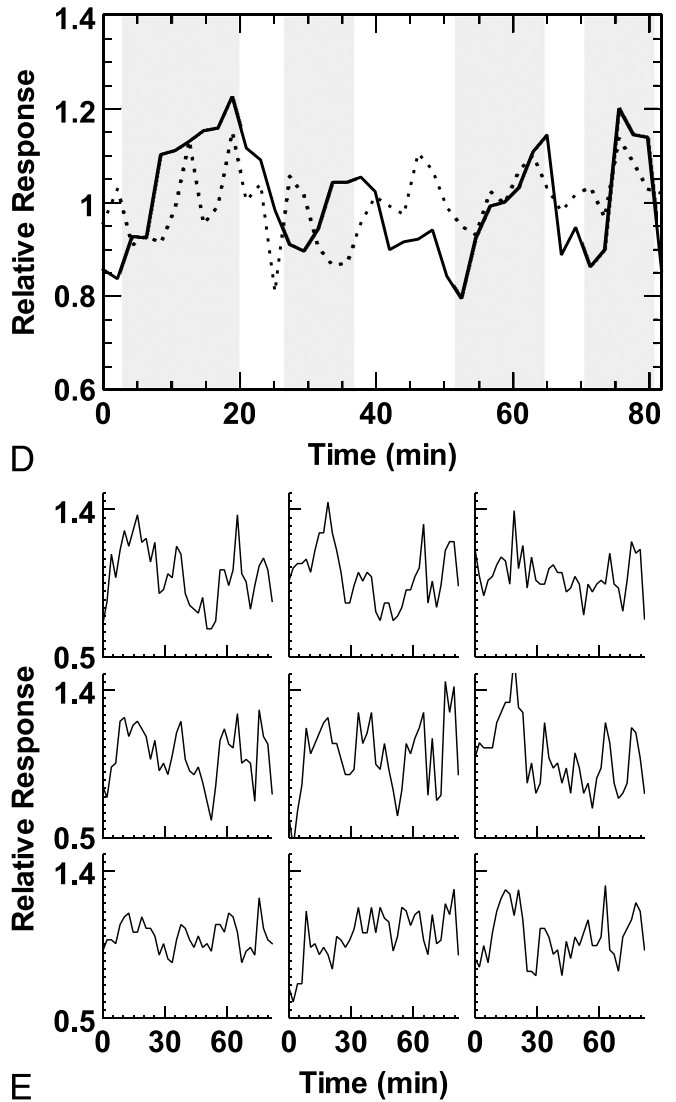

FIGURE 4. T2*-weighted images of BAT activation. A, Design of the cooling protocol for dynamic T2* imaging. The duration and timing of thermoneutral (white), cold (dark grey), and mild cold conditions (light grey) are shown. B, T1-weighted (anatomical) axial MRI slice. C, The T2*-weighted slice corresponding to the slice in (B). D, Normalized signal fluctuations averaged from a $3 \times 3$ voxels large ROI in muscle (dotted lines) and BAT (solid line). The location of the ROls is shown in (B). The grey areas represent the time points at which the participant was exposed to cold or mild cold conditions. The BAT T2* signal shows fluctuations with a characteristic temporal signature that correlates with the cooling paradigm. $\mathrm{E}$, The individual time traces in the $3 \times 3$ BAT ROI shows the signal heterogeneity in the ROI. 


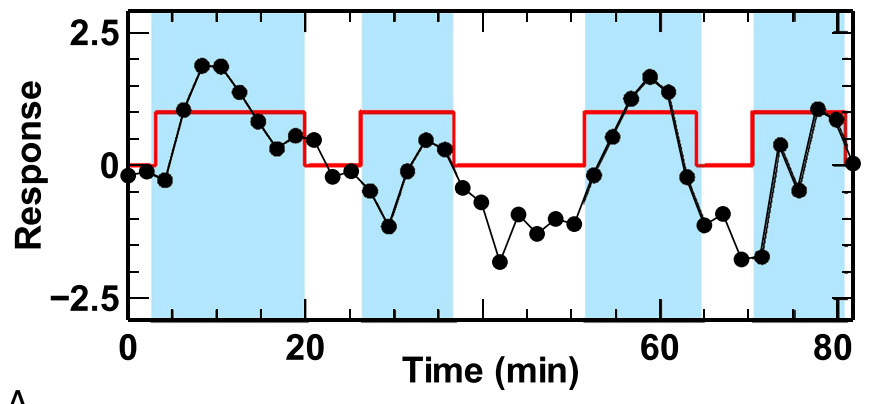

A

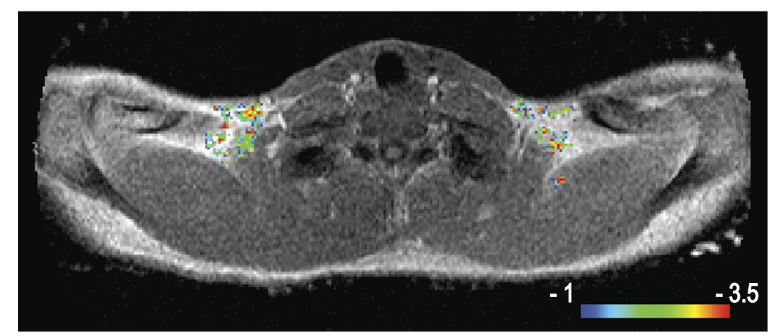

B

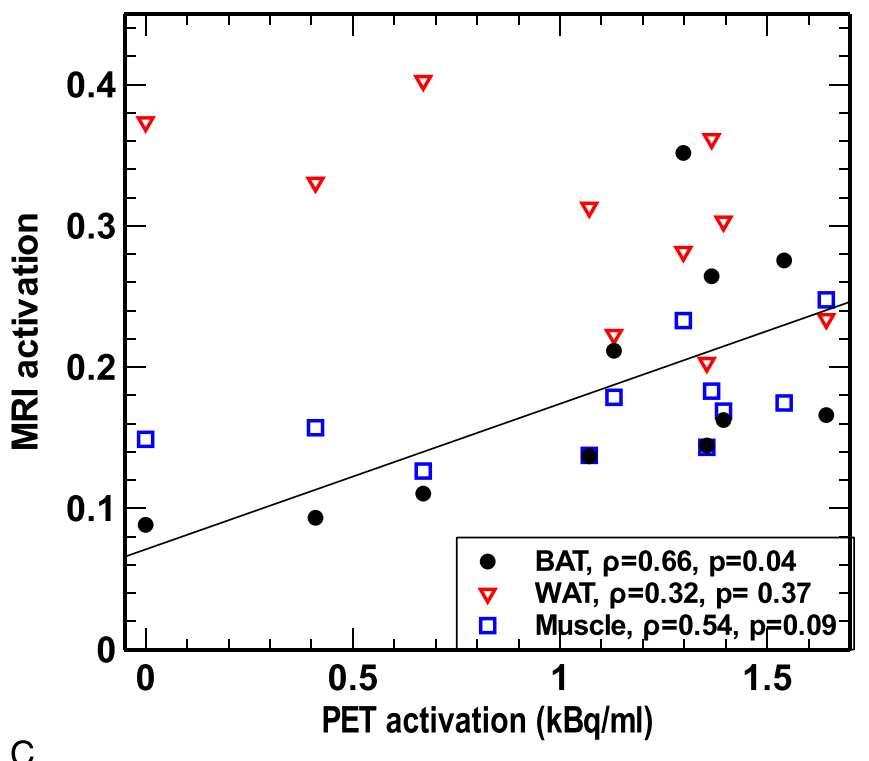

FIGURE 5. Analysis of BAT activation during T2* imaging compared with PET. A, Example of a component identified by the ICA (black circles). The component is modeled as a square wave with a value of 1 during cold exposure and 0 during thermoneutral conditions (red line). The blue areas indicate the time points during which the participants were exposed to cooling and mild cold conditions. B, Overlay of a color-coded activation map of the supraclavicular/cervical fat depot onto an axial slice of a T1-weighted MRI image. C, Scatterplot of BAT activation in all participants as measured by PET (FDG uptake in kilobecqerels per milliliters) and MRI (the fraction of activating pixels in the supraclavicular/cervical ROI). The activation was also measured in muscle, WAT, and BAT.

applicability and validity of these techniques have not been shown in human adults. This study is an exploration of the use of MRI for identifying active BAT in adult humans. 2-Deoxy-2-[18F]fluoro-Dglucose-PET was used as the reference standard because this technique has been shown to reliably detect active BAT depots. ${ }^{20}$
The MRI-derived fat fraction of the supraclavicular/cervical adipose depot was approximately $66.0 \%$, which was considerably lower compared with the subcutaneous WAT with a fat fraction of $81.5 \%$. Using a similar MRI method for water-fat separation in rats, $\mathrm{Hu}$ et $\mathrm{al}^{6}$ found a fat fraction of approximately $50 \%$ for juveniles increasing to $60 \%$ at older age. Recent evidence suggests that the fat content in BAT of newborn humans is lower than that in WAT. ${ }^{10}$ The fat fraction in the supraclavicular/cervical adipose depots measured in our study is thus in a similar range as has been reported for BAT. However, our results may suggest that the fat fraction is a general property of these depots and may not be representative of the presence of active BAT. First, the fat fraction of the regions in the supraclavicular/cervical depots showed that FDG uptake was not significantly different from the adjacent adipose tissue. The regions showing FDG uptake on the PET were visually indiscernible from the adjacent adipose tissue on the MRI fat-content images. Second, the fat fraction of the supraclavicular/cervical fat depots did not correlate with the FDG uptake on the PET/CT. Whether this is related to cellular or tissue organizational differences cannot be determined at this spatial resolution. Recent studies suggest that the human supraclavicular and cervical adipose depot is a mix of brown and white adipocytes, in contrast to the distinct BAT depots found in rodents. ${ }^{21,22}$ In humans, brown adipocytes were found to be organized in small islands and the depot contained, on average, $13 \%$ brown adipocytes. ${ }^{22}$ Identification of active BAT based on tissue fat content alone might therefore be difficult in adult humans. Performing simultaneous PETMRI could provide a more accurate characterization of BAT properties. A more reliable delineation of active BAT with the water-fat MRI would provide a more accurate segmentation of the BAT depot and, thus, a better estimate of active BAT fat content.

Brown adipose tissue activation is associated with enhanced tissue perfusion. ${ }^{23}$ Increased blood flow would support the higher metabolic rate. ${ }^{24}$ In addition, for effective thermogenesis, the produced heat needs to be transported to the body core tissues. T2*-weighted imaging has been extensively used to map brain perfusion in functional MRI but has also been successfully applied to other tissues such as the skeletal muscle ${ }^{25,26}$ and the spinal cord. ${ }^{27,28}$ Recent work by Khanna and Branca ${ }^{9}$ using T2*-weighted imaging in mice has shown that image contrast was sensitive to pharmacological activation of BAT. During cold activation, we observed $\mathrm{T} 2 *$-weighted signal fluctuations from BAT that coincided temporally with the cold stimulus. The presence of such a component suggests that BAT on/off switching is rapid and occurs at the scale of minutes. Such a temporal response corresponds to a sympathetic activation of BAT as found in rodents. ${ }^{3}$ The identification of this component was confirmed by the ICA, which has been proven a useful technique in identifying physiological responses in brain functional MRI. ${ }^{29}$ The presence of such signal components, as quantified by the model-based regression analysis, correlated with BAT activity. This means that the T2*-weighted signal is sensitive to BAT activation. However, the origin of this signal is not yet completely clear. In the brain, the $\mathrm{T} 2 *$-weighted signal is sensitive to perfusion through the blood oxygenation level-dependent (BOLD) effect, which influences the $\mathrm{T} 2 *$ decay. The decrease in the concentration of deoxyhemoglobin in well-perfused vessels causes a small signal increase in the order of 3\% to $5 \%$ at $3 \mathrm{~T}$. The magnitude of the signal changes observed in BAT was much larger and therefore cannot be attributed to the BOLD effect alone. Larger fluctuations in the $\mathrm{T} 2 *$-weighted signal may have a different physiological origin as has been suggested previously in the spine and the muscle. ${ }^{30,31}$ The T2*-weighted signal is sensitive to numerous other effects, such as blood volume, motion, and $\mathrm{T} 1$ relaxation time effects such as blood in/out flow. In addition, a priori, it remains unknown whether (absolute and/or relative) BOLD responses are similar in neuronal, muscle, and adipose tissue for reasons of likely differences between tissue background signal, metabolism, and coupling between blood vessels and tissue. Pinpointing the mechanisms underlying the 
sensitivity to BAT activation is challenging. First of all, the sign of the signal change was undetermined because both were present and correlated with BAT activity. In addition, the image quality suffered from several artifacts. Breathing artifacts in the lung region and pulsation artifacts from the carotid arteries were visible on the T2*-weighted images. Compared with $\mathrm{T} 2 *$-weighted imaging of the brain, movement artifacts are more difficult to correct because of the nonrigid nature of the anatomy under consideration. All of these effects contribute to some extent to the $\mathrm{T} 2 *$-weighted signal and therefore might also explain the low specificity of measuring BAT activation with the proposed method. For instance, in the muscle, we found that the fraction of activating voxels showed a similar trend as that of BAT. However, this trend was weaker than that of BAT and not statistically significant. Whether this is a biological effect (for instance, through reduced muscle perfusion to reduce heat loss), an effect of movement artifacts or signal from BAT spreading through phase artifacts remains to be determined. Therefore, the use of MRI needs to be further refined before matching the specificity of FDGPET/CT for the identification of active BAT. However, the presence of signal components that correlate with FDG uptake is promising for the identification of BAT using perfusion-based MRI methods.

In summary, we have presented a functional and structural MRI exploration of BAT in humans combined with FDG-PET/CT. Water-fat imaging using MRI showed that active BAT cannot be discerned on the basis of tissue fat content. Dynamic imaging of BAT activation using T2*-weighted MRI during cold stimulation is promising for the identification of active BAT. During cold stimulation, BAT activation modulated the $\mathrm{T} 2 *$-weighted signal. Although $\mathrm{T} 2 *$-weighted image contrast seemed sensitive to activation, MRI of BAT is challenging because of the presence of susceptibility and physiological artifacts. Compared with $\mathrm{T} 2 *$-weighted MRI, activated BAT can be identified by FDG-PET with a stronger contrast. However, in contrast to MRI, temporal and quantitative information on tissue fat content is lacking. Additional advanced MRI techniques, such as spin-echo echo-planar imaging and arterial spin labeling, can be used to obtain more detailed information on changes in blood flow, volume, and oxygenation of active BAT. Future work will also need to focus on the tailoring of an MRI method that is both sensitive and specific enough to make full use of the advantages of MRI over PET/CT and that stimulates research on combined PET/MRI systems. ${ }^{32,33}$

\section{REFERENCES}

1. Cinti S. Between brown and white: novel aspects of adipocyte differentiation. Ann Med. 2011;43:104-115.

2. Wijers SL, Saris WH, van Marken Lichtenbelt WD. Recent advances in adaptive thermogenesis: potential implications for the treatment of obesity. Obes Rev. 2009;10:218-226.

3. Cannon B, Nedergaard J. Brown adipose tissue: function and physiological significance. Physiol Rev. 2004;84:277-359.

4. Vijgen GH, Bouvy ND, Teule GJ, et al. Brown adipose tissue in morbidly obese subjects. PLoS One. 2011;6:e17247.

5. Branca RT, Warren WS. In vivo brown adipose tissue detection and characterization using water-lipid intermolecular zero-quantum coherences. Magn Reson Med. 2011:65:313-319.

6. Hu HH, Smith DL Jr, Nayak KS, et al. Identification of brown adipose tissue in mice with fat-water IDEAL-MRI. J Magn Reson Imaging. 2011;31:1195-1202.

7. Chen YI, Cypess AM, Sass CA, et al. Anatomical and functional assessment of brown adipose tissue by magnetic resonance imaging. Obesity (Silver Spring). 2012;20:1519-1526.

8. Sbarbati A, Cavallini I, Marzola P, et al. Contrast-enhanced MRI of brown adipose tissue after pharmacological stimulation. Magn Reson Med. 2006;55: $715-718$.
9. Khanna A, Branca RT. Detecting brown adipose tissue activity with BOLD MRI in mice. Magn Reson Med. 2012;68:1285-1290.

10. Hu HH, Tovar JP, Pavlova Z, et al. Unequivocal identification of brown adipose tissue in a human infant. J Magn Reson Imaging. 2012;35:938-942.

11. Dixon WT. Simple proton spectroscopic imaging. Radiology. 1984;153:189-194

12. Ouellet V, Labbe SM, Blondin DP, et al. Brown adipose tissue oxidative metabolism contributes to energy expenditure during acute cold exposure in humans. J Clin Invest. 2012;122:545-552.

13. Kuhn JP, Evert M, Friedrich N, et al. Noninvasive quantification of hepatic fat content using three-echo Dixon magnetic resonance imaging with correction for T2* relaxation effects. Invest Radiol. 2011;46:783-789.

14. Szumowski J, Coshow WR, Li F, et al. Phase unwrapping in the three-point Dixon method for fat suppression MR imaging. Radiology. 1994;192:555-561.

15. Kang BK, Yu ES, Lee SS, et al. Hepatic fat quantification: a prospective comparison of magnetic resonance spectroscopy and analysis methods for chemical-shift gradient echo magnetic resonance imaging with histologic assessment as the reference standard. Invest Radiol. 2012;47:368-375.

16. Rueckert D, Sonoda LI, Hayes C, et al. Nonrigid registration using free-form deformations: application to breast MR images. IEEE Trans Med Imaging. 1999;18:712-721.

17. Beckmann CF, Smith SM. Probabilistic independent component analysis for functional magnetic resonance imaging. IEEE Trans Med Imaging. 2004;23: $137-152$

18. Smith SM, Jenkinson M, Woolrich MW, et al. Advances in functional and structural MR image analysis and implementation as FSL. Neuroimage. 2004;23(suppl 1):S208-219.

19. Woolrich MW, Jbabdi S, Patenaude B, et al. Bayesian analysis of neuroimaging data in FSL. Neuroimage. 2009:45:S173-S186.

20. Virtanen KA, Lidell ME, Orava J, et al. Functional brown adipose tissue in healthy adults. $N$ Engl J Med. 2009;360:1518-1525.

21. van Marken Lichtenbelt WD, Vanhommerig JW, Smulders NM, et al. Coldactivated brown adipose tissue in healthy men. $N$ Engl J Med. 2009;360: 1500-1508.

22. Zingaretti MC, Crosta F, Vitali A, et al. The presence of UCP1 demonstrates that metabolically active adipose tissue in the neck of adult humans truly represents brown adipose tissue. FASEB J. 2009;23:3113-3120.

23. Orava J, Nuutila P, Lidell ME, et al. Different metabolic responses of human brown adipose tissue to activation by cold and insulin. Cell Metab. 2011;14 272-279.

24. Foster DO, Frydman ML. Tissue distribution of cold-induced thermogenesis in conscious warm- or cold-acclimated rats reevaluated from changes in tissue blood flow: the dominant role of brown adipose tissue in the replacement of shivering by nonshivering thermogenesis. Can J Physiol Pharmacol. 1979;57: $257-270$

25. Versluis B, Backes WH, van Eupen MG, et al. Magnetic resonance imaging in peripheral arterial disease: reproducibility of the assessment of morphological and functional vascular status. Invest Radiol. 2011;46:11-24.

26. Ledermann HP, Schulte AC, Heidecker HG, et al. Blood oxygenation leveldependent magnetic resonance imaging of the skeletal muscle in patients with peripheral arterial occlusive disease. Circulation. 2006;113:2929-2935.

27. Stroman PW, Tomanek B, Krause V, et al. Mapping of neuronal function in the healthy and injured human spinal cord with spinal fMRI. Neuroimage. 2002; 17:1854-1860.

28. Backes WH, Mess WH, Wilmink JT. Functional MR imaging of the cervica spinal cord by use of median nerve stimulation and fist clenching. AJNR Am J Neuroradiol. 2001;22:1854-1859.

29. McKeown MJ, Jung TP, Makeig S, et al. Spatially independent activity patterns in functional MRI data during the Stroop color-naming task. Proc Natl Acad Sci U S A. 1998;95:803-810.

30. Stroman PW. Magnetic resonance imaging of neuronal function in the spinal cord: spinal FMRI. Clin Med Res. 2005;3:146-156.

31. Kos S, Klarhofer M, Aschwanden M, et al. Simultaneous dynamic blood oxygen level-dependent magnetic resonance imaging of foot and calf muscles: aging effects at ischemia and postocclusive hyperemia in healthy volunteers. Invest Radiol. 2009;44:741-747.

32. Bini J, Izquierdo-Garcia D, Mateo J, et al. Preclinical evaluation of MR attenuation correction versus CT attenuation correction on a sequential wholebody MR/PET scanner. Invest Radiol. 2013;48:313-322.

33. Stolzmann $\mathrm{P}$, Veit-Haibach $\mathrm{P}$, Chuck N, et al. Detection rate, location, and size of pulmonary nodules in trimodality PET/CT-MR: comparison of low-dose CT and Dixon-based MR imaging. Invest Radiol. 2013;48:241-246. 